\title{
La Artesanía: patrimonio e identidad cultural
}

\author{
DOI: http://dx.doi.org/10.5377/koot.v0i9.5908
}

URI: http://hdl.handle.net/11298/438

\author{
Dr. Ramón D. Rivas \\ Antropólogo Social y Cultural \\ Director de Cultura \\ Universidad Tecnológica de El Salvador \\ ramon.rivas@utec.edu.sv
}

\section{Resumen}

En este artículo se plantea la importancia que tiene el sector artesanal en el fenómeno de la identidad cultural de los pueblos y además, conceptualiza lo que entendemos como artesanía desde la perspectiva antropológica; la diferencia que se debe hacer entre artesanía tradicional y la artesanía contemporánea. Analiza además, brevemente, la importancia que tiene la artesanía como parte del patrimonio cultural, la identidad de los pueblos y como recurso económico.

El artículo finaliza haciendo referencia sobre la artesanía y su diferenciación con las manualidades, con la única finalidad de crear insumos que ayuden a reflexionar sobre la importancia de proteger este rubro, apropiarse de él y así poderlo heredar a las futuras generaciones.

El interés se ubica desde la perspectiva antropológica, y de ello lo importante que es para la sociedad, su valor patrimonial y cultural.

Palabras clave: Identidad cultural - El Salvador, Artesanías, Antropología, Patrimonio cultural - El Salvador

\begin{abstract}
This article shows the importance of the handicraft industry in the phenomenon of the cultural identity of the peoples taken into account how the anthropological perspective conceptualizes it; the difference found between traditional craftsmanship and contemporary craftsmanship. It also analyzes, briefly, the importance of crafts as part of cultural heritage, the identity of peoples and as economic resources.
\end{abstract}

The article ends with reference to craftsmanship and its differentiation with crafts, with the exclusive purpose of creating input in order to reflect on the importance of protecting this trading name, to seize it and thus to be able to inherit to the future generations 
The anthropological perspective highlights its interest in approaching this topic which is important for the society, its heritage and cultural value.

Palabras clave: Cultural identity - El Salvador, Handicrafts, Anthropology, Cultural heritage - El Salvador.

\section{Introducción}

¿Qué debemos entender cómo artesanía?

Según Enrique Roncancio (1999), la artesanía es el resultado de la creatividad y la imaginación, plasmado en un producto en cuya elaboración se han transformado racionalmente materiales de origen natural, generalmente con procesos y técnicas manuales. Los objetos artesanales van cargados de un alto valor cultural y debido a su proceso son piezas únicas.

Es importante señalar que cada objeto artesanal es diferente de los demás, incluso cuando se reproduce en grandes cantidades, ya que cada uno depende de la composición de su materia prima. Son piezas únicas que no pueden igualarse la una con la otra, aunque se haya hecho muy parecida. Esto le da un valor muy alto, ya que su creación manual y única, permite al artesano poner toda su creatividad e imaginación en su obra.

Lo anterior debe llevarnos a preguntar: ¿En qué momento nace la artesanía? ¿Por qué el ser humano creó este tipo de producto?

No tenemos fecha o espacio histórico donde ubicar al surgimiento exacto de la artesanía. No obstante, creemos que este tipo de expresión humana es tan antigua como la humanidad misma. Nace desde el mismo momento que el ser humano quiere materializar su concepción de la vida, o de representar su idea de los dioses a los cuales adora y respeta; o también, cuando quiere simplificar la vida cotidiana, para lo cual tuvo que crear sus propios utensilios, herramientas $\mathrm{y}$ todo aquellos que le fue indispensable para vivir y transformar su entorno natural, llámese: vestimentas, utensilios de cocina, herramientas de trabajo, entre otras.

De ahí que, según el desarrollo de los pueblos, la artesanía podía diferenciarse de un pueblo a otro. Además, el uso de técnicas e instrumentos de trabajo vendría a caracterizar el objeto o artesanía creada. Por ejemplo, la transformación del oro, la plata o el bronce en los países, depende del desarrollo cultural y de la técnica utilizada por el artesano. 


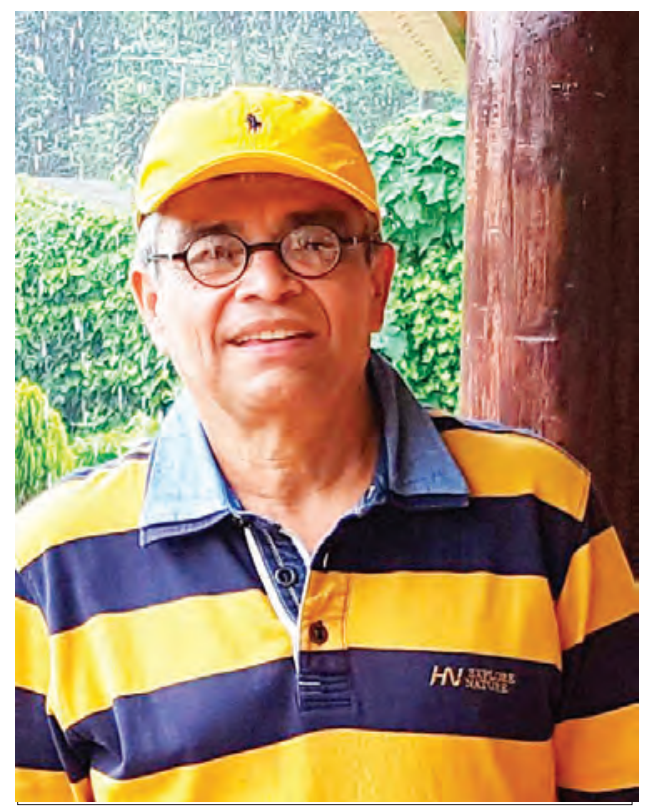

Dr. Ramón D. Rivas

De la anterior afirmación, quiero identificar los dos tipos de artesanías que podemos encontrar en un pueblo:

a) La artesanía tradicional, la cual se produce desde tiempos ancestrales y en las cuales se conservan, sin mucha variación, las técnicas, los diseños y hasta los colores originales; e identifican el lugar de origen del producto.

b) La artesanía contemporánea, consistente en productos que conservan gran parte del proceso de elaboración que las tradicionales, pero que sufren modificaciones para satisfacer nuevas necesidades materiales y espirituales.

Con la caracterización hecha, es importante ubicar la artesanía que elaboran los artesanos salvadoreños para impulsar políticas que contribuyan a fortalecer su desarrollo o rescatar su proceso para darle el valor real que se merecen, ya que, si no le damos el valor real, entonces, la sociedad no podrá discernir entre patrimonio y un simple producto de uso diario sin valor cultural.

Esto lo pude constatar en un viaje hecho a China, Taiwan, lugar donde se valora mucho el trabajo artesanal tradicional. Recuerdo que cuando fui llevado al Museo Nacional, donde pude constatar la técnica artesanal utilizada en esa región para trabajar el jade, me impresionó mucho un pequeño libro de no más de un centímetro de diámetro y en donde se había escrito una historia. Ellos 
trabajan el oro en una forma extraordinaria, todo manualmente, al punto de dejar sorprendido a cualquiera que lo observa.

Con esto puedo asegurar que la artesanía puede definirse también como un conjunto de técnicas tradicionales y manuales que tienen un valor de patrimonio cultural, actualmente amenazado o en vías de desaparición, en particular porque se basa en una "tradición oral".

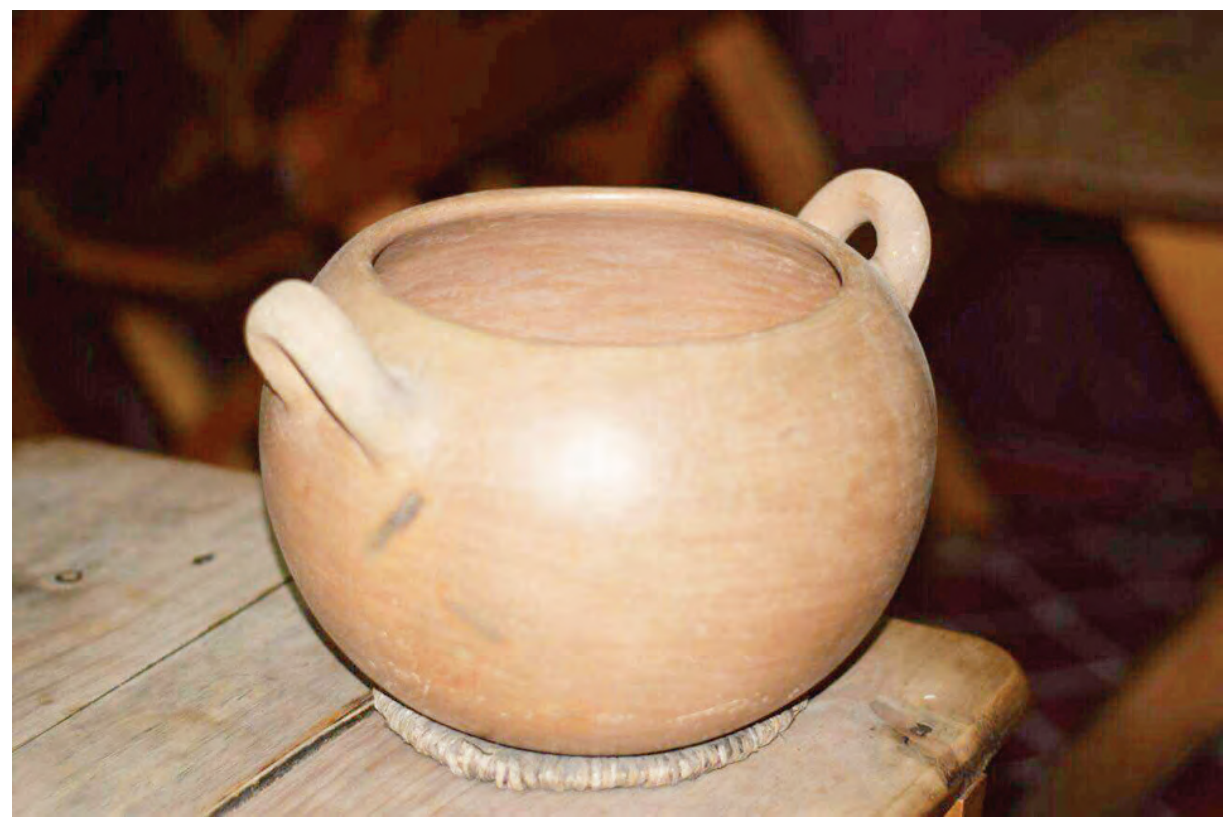

Olla frijolera. Fotografía: Gerardo Herrera.

\section{Ubiquemos entonces a la artesanía como Patrimonio cultural}

Con la anterior afirmación, llegamos al segundo punto de nuestro tema, y este consiste en ubicar a la artesanía como patrimonio cultural, sobre todo, porque por medio de la artesanía, los pueblos pueden identificarse, trasladar la técnica de generación a generación; sentirse representados al ver su producto en otros lugares fuera de su tierra de origen.

La artesanía como patrimonio cultural permite al artesano ser muy cuidadoso en heredar su conocimiento y pulir la habilidad en sus herederos, ya sean estos su familia y los mismos trabajadores que acompañaron al experto en la tarea de producir. En la antigüedad, eran sobre los artesanos en quien recaía, en las sociedades tradicionales, la responsabilidad de proporcionar a su familia y a la comunidad los elementos indispensables para la vida diaria. Hoy en día, a esto lo conocemos como "cultura popular", el cual es definido por el Antropólogo 
guatemalteco Celso Lara Figueroa como "el crisol donde se refugian los valores más auténticos que una nación ha creado a lo largo de su devenir histórico, y nutrido diariamente por la realidad socioeconómica que rige su vida colectiva".

Ejemplo de lo anterior lo constituye Ilobasco, un pueblo que por décadas ha promovido y protegido su patrimonio artesanal, donde la cultura del barro ha permitido a miles de ilobasquenses a ser emprendedores, a sentirse orgullosos de su tierra y a saber identificarse por medio de su cultura del barro.

Ya lo he dicho en otras ocasiones, que debemos proteger nuestro patrimonio cultural porque da identidad a los pueblos, expresa la capacidad que tenemos para crear y dar testimonio de nuestra manera de vivir, de reflejar nuestra realidad y de coexistir con otros grupos sociales. Además, el patrimonio cultural es el soporte clave de la historia de la humanidad, donde cada obra creada, tangibles o intangibles, sirve como testimonio cultural que da sentido de pertenencia a pueblos y naciones.

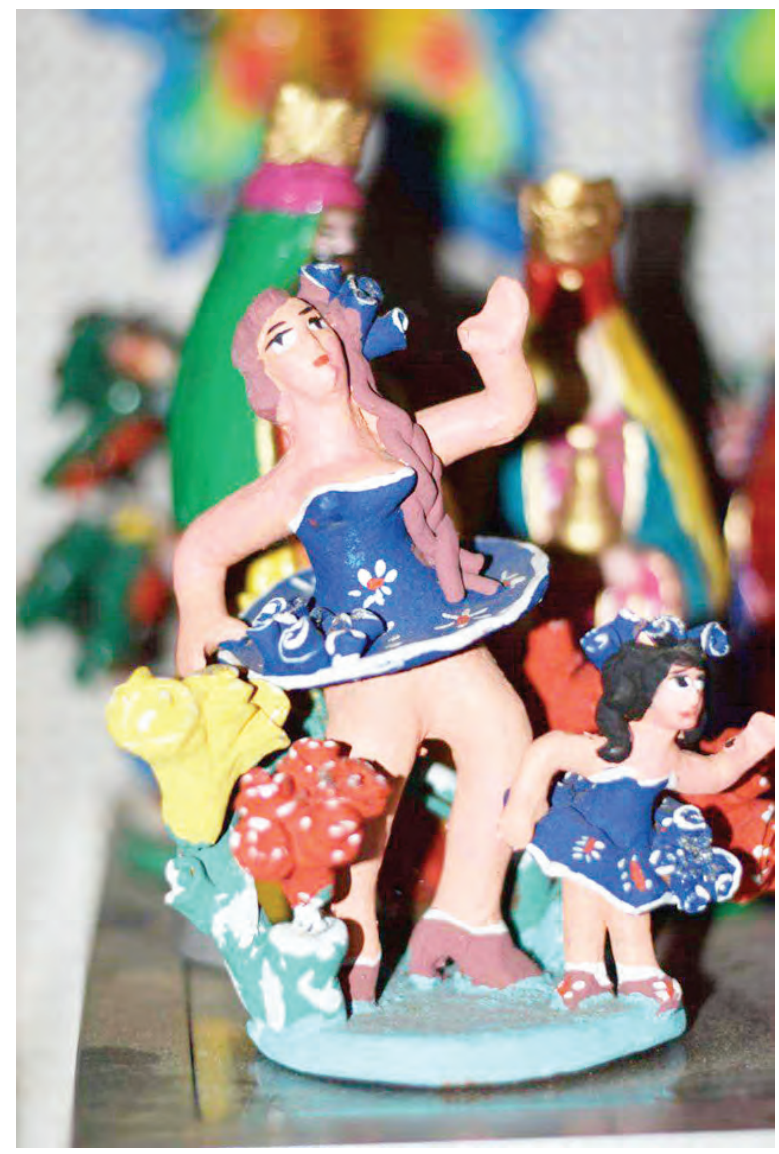

Muñequitos de barro. Fotografía: Gerardo Herrera. 
Hago énfasis en lo anterior, sobre todo, porque el patrimonio da un sentido de pertenencia a los individuos en el seno de una colectividad mayor. En la actualidad, se considera que el patrimonio constituye una serie de elementos asociados con las raíces, la identidad, la ubicación espacial y la filiación de las personas; refiere además a los usos contemporáneos del pasado para una gran variedad de metas estratégicas, ya sea de índole económica o de particular relevancia para las construcciones identitarias (Hoelscher, 2006).

Para ser más explícito en esto, la UNESCO en su convención realizada en el 2003, solicitó a los estados miembros, a salvaguardar las técnicas vinculadas a la artesanía tradicional, ya que forman parte del patrimonio inmaterial. Esas técnicas son la expresión de la historia, la cultura y la identidad de los pueblos, cuya continuidad encarnan. En palabras de Jocelyne Etienne-Nugue, investigadora de este tema, "en la medida en que son testigos de una sociedad y de una época, los objetos artesanales reflejan la identidad de los hombres que los fabrican y los utilizan, así como sus tradiciones: estilos de vida, costumbres, ceremonias, valores sociales, religiosos y morales".

Por ello, las sociedades modernas buscan desplazar y producir al menor costo posible, la UNESCO destaca y alienta a los estados a promover en las comunidades donde se produce artesanías, el empleo de los medios más eficaces para esta salvaguardia, como los inventarios de conocimientos y técnicas, su transmisión del maestro a los alumnos, la identificación de los "tesoros humanos vivos", depositarios talentosos de un legado ancestral y portadores de las tradiciones.

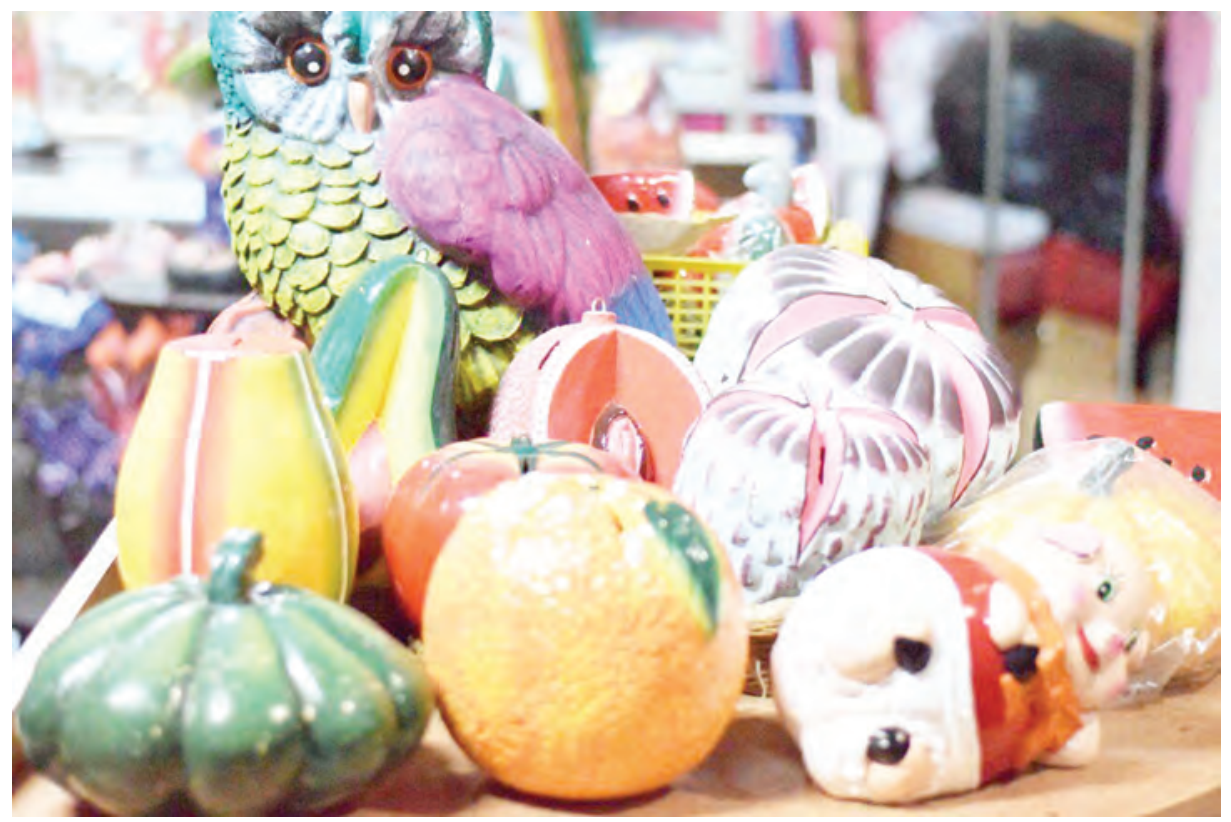

Variedad artesanal en barro. Fotografía: Gerardo Herrera. 


\section{¿Cómo podemos mantener y fortalecer nuestro patrimonio artesanal?}

Considero que estimulando a las nuevas generaciones para que no olviden su pasado y sus orígenes. Para ellos hay que hacer conciencia sobre la artesanía como patrimonio cultural; además, se debe brindar formación con maestros competentes; se debe proponer una visión moderna de la artesanía gracias a la tecnología; potenciar los intercambios con los artesanos de otros países; y se debe mejorar la capacidad de comercialización de los artesanos en el mercado internacional, proporcionándoles información y conocimientos técnicos.

Desde esta perspectiva, es de suma importancia darle más valor al trabajo que desarrollan en nuestra sociedad salvadoreña. El aporte de ustedes para la cultura y nuestra identidad, es grande; y considero que existen artesanías en nuestro país que han ido desapareciendo por el poco apoyo que han tenido por parte de las autoridades locales y nacionales; así como por el poco conocimiento que se tiene sobre su impacto cultural que tiene en la sociedad misma.

Ilobasco, es un pueblo importante para El Salvador, no solo por su aporte al desarrollo económico que brinda por medio de la ganadería, la agricultura del maíz, el comercio y a la alfarería; sino también, por su gran contribución a la cultura salvadoreña. Ilobasco es la cuna artesanal donde se promueven las más viejas tradiciones del barro.

Pero es importante recalcar que El Salvador no debe ser conocido solo por las artesanías de Ilobasco y La Palma; también deben destacar las artesanías de Guatajiagua, San Sebastián y otras mucha más. Conservar nuestra artesanía, es conservar la identidad como pueblo; una identidad tan poderosa que ha conservado y exportado nuestras creencias, nuestras costumbres y nuestras "picardías" envueltas en pequeñas sorpresas, como la hacen los artesanos de Ilobasco.

En cuanto a la artesanía como recurso económico, se puede reflexionar y escribir mucho de ello; pero haré énfasis en algunos aspectos de los cuales los antropólogos nos sentimos bastantes preocupados.

Todos sabemos que, en una sociedad de consumo, el uso de prenda elaboradas industrialmente con materiales dañinos al medio ambiente, desplaza cada vez más la producción artesanal de nuestros pueblos. Conseguir la materia prima para elaborar artesanía es cada vez más costoso. En los países más pobres y las sociedades fuertemente apegadas a sus tradiciones, la artesanía sigue siendo una producción ligada a funciones utilitarias y a un modo de vida. No obstante, esas poblaciones sienten la tentación de utilizar los nuevos productos de origen industrial a los que tienen acceso. Y es así como el plástico y la hojalata reemplazan, poco a poco, a la paja y la arcilla, y las prendas menos caras de algodón estampado sustituyen a los pesados tejidos y las sedas pintadas a mano. En la fiera competencia que impone el mercado, la artesanía muchas veces 
queda en desventaja ante productos fabricados masivamente. Esto debemos ponerle mucha atención, porque no solo afecta la parte económica de las familias que viven de la artesanía; sino que también. Porque afecta la parte cultural y patrimonial como lo vimos anteriormente.

Creo que la artesanía no debe ser elaborada únicamente como producto nostálgico para los compatriotas que están fuera de nuestras tierras; ya sea en Estados Unidos, Australia o en cualquier otra región del mundo. Tampoco debe ser vista como simples recuerdos para turistas que llegaron a nuestras tierras y desearon llevarse un accesorio, supuestamente fabricados por manos de artesanos y que nos identifica como pueblo. Nada más falso esa concepción de artesanía como recurso económico.

Lo que se debe impulsar, es una política pública en donde el producto artesanal, de mayor calidad que lo industrial, forme parte de nuestra economía, del uso diario de nuestra gente, parte fundamental del mercado local y nacional. Debe haber incentivos para que la artesanía salvadoreña dignifique a su gente, la haga sentirse identificada y orgullosa de portarla y consumirla.

Por ejemplo, adquirir muebles fabricados en Nahuizalco debería ser la primera opción del consumidor que irse a cualquier almacén a adquirir muebles con telas sintéticas y con pocos detalles de las que pueda lucir un mueble elaborado por un ebanista salvadoreño.

Pero esto implica también capacitar a los artesanos, ya que deben poner productos de calidad que sobrepasen la durabilidad de los productos fabricados por las fábricas, en donde la cantidad es el fin y no la calidad. Para ello, nuestros artesanos, deben estar muy bien organizados desde sencillos talleres familiares hasta formales empresas. No se puede competir en un mercado globalizado de forma individual y con productos elaborados sin las técnicas de nuestros ancestros. Se debe crear centros de producción para la economía de nuestros pueblos, elaborando productos que, en opinión de los expertos, constituyen verdaderas obras de arte tradicional y contemporánea, provocando la admiración de propios y extraños.

Considero que las técnicas empleadas por nuestros ancestros en las artesanías que elaboraron, deben continuar. No obstante, sabemos que la artesanía moderna se orienta hacia una creatividad innovadora que utiliza técnicas novedosas y nuevas tecnologías. Esto es bueno, pero como antropólogo considero que lo nuevo no debe reemplazar lo antiguo, sobre todo en materia cultural, ya que ello implicaría pérdida de nuestra identidad y nuestro pasado.

Estamos claros que el diseño aparece como una prolongación de la artesanía, confirmada además por las creaciones de los artesanos seleccionados para las exposiciones y los concursos. Pero esto no debe ser excusa para reemplazar técnicas y métodos que indican cultura e identidad. Esa es la tarea. 


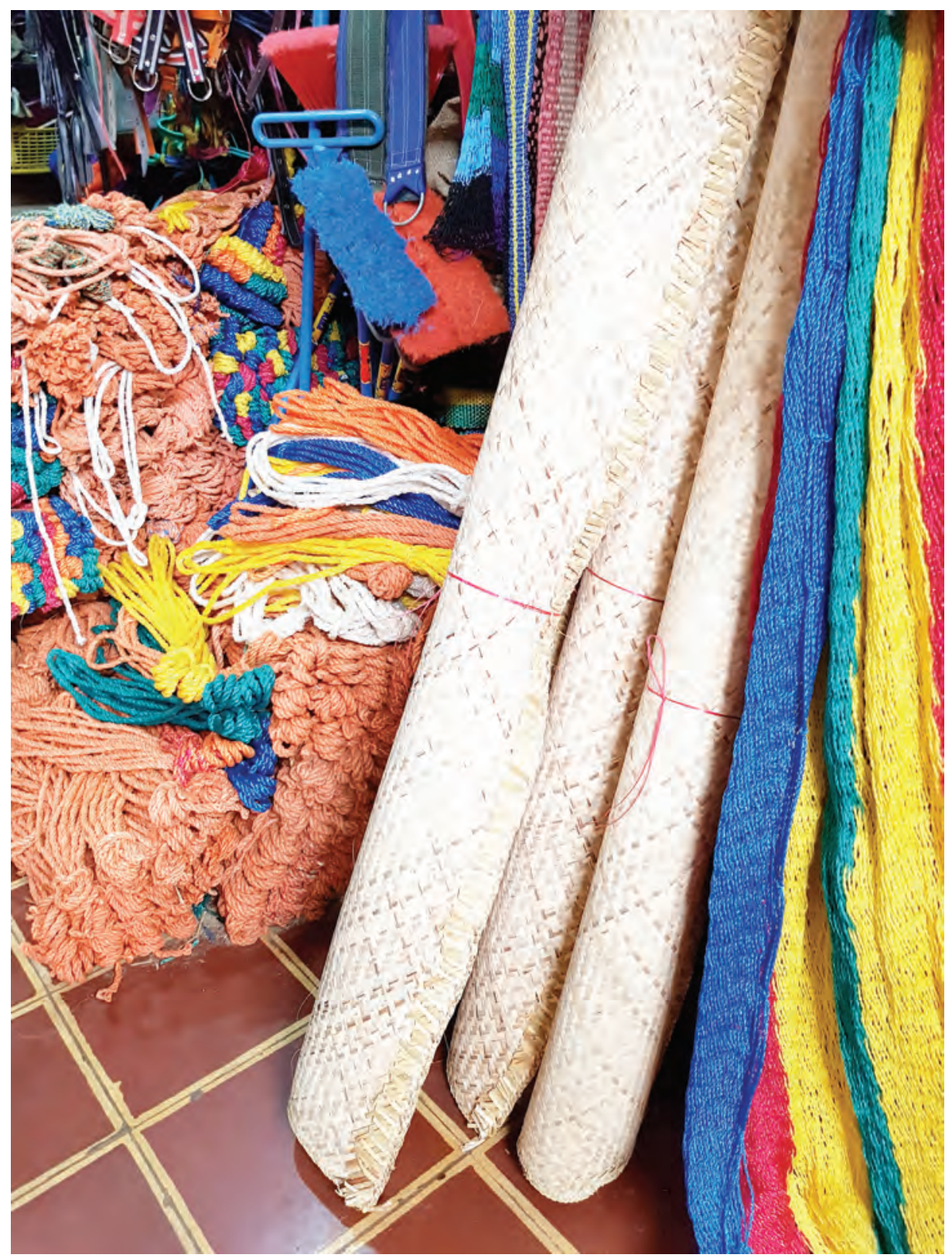

Petates de tule, lazos y hamacas de nylon. Fotografía: Gerardo Herrera.

Otro aspecto importante en materia económica lo constituye el reciclaje. El mundo moderno cada vez destruye su hábitat y lo contamina permanentemente. Si el artesano se convertir en parte de la solución para contrarrestar la contaminación, haciendo artesanía de materiales reciclables, creería que sería 
una buena alternativa emprendedora para aliviar la permanente contaminación que hacemos a nuestro planeta.

Ya en 1993, con motivo de una gran exposición sobre las artesanías del mundo titulada "Recuperación, invención, creatividad", la UNESCO hizo referencia al "arte de utilizar los desechos para convertirlos en objetos ingeniosos, útiles y agradables”. La pregunta es ahora: ¿Cuánto hemos avanzado en esta propuesta hecha por el organismo internacional? Al menos en El Salvador considero que no conozco iniciativas de impacto que estén enmarcadas en la propuesta de la UNESCO.

La recuperación y el reciclaje son medios de lucha contra la contaminación y el despilfarro. Son por tanto factores de desarrollo sostenible. Y como todos lo sabemos, la finalidad del desarrollo sostenible es favorecer el desarrollo de los pueblos en todas sus actividades; a fin de reducir la pobreza en el mundo. Toca pues a cada uno de ustedes reflexionar un poco más en este tema para encontrar una oportunidad de desarrollo para este importante sector de la sociedad salvadoreña.

\section{Diferenciación entre artesanía y manualidades.}

Ya en el inicio de este artículo conceptualizamos lo que entendemos como artesanía, el cual es un producto que resulta de la creatividad y la imaginación del artesano; y en donde los procesos y técnicas para la transformación de la materia de origen natural, se hace generalmente manualmente o con instrumentos artesanales propios de la región.

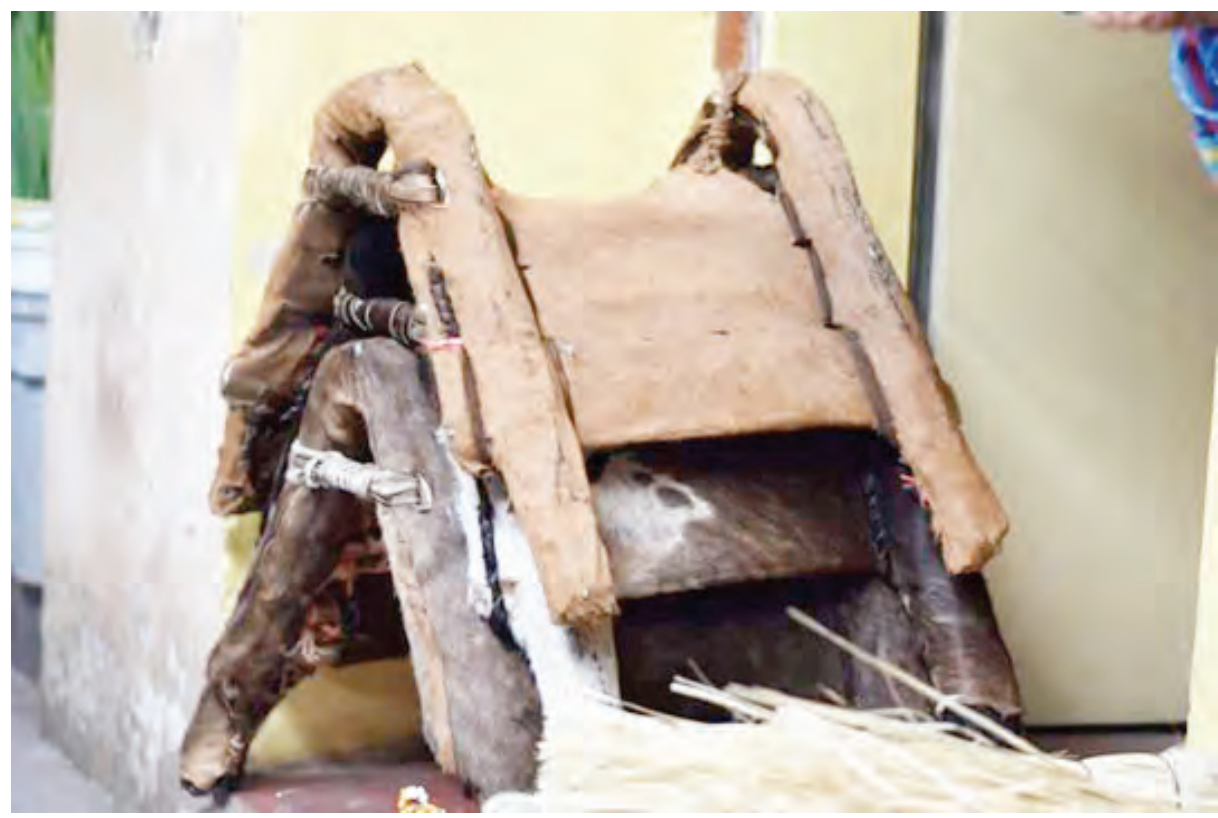

Aparejos de cuero crudo. Fotografía: Gerardo Herrera. 
Con esta definición queda claro que una artesanía es un objeto o producto de identidad cultural comunitaria, sobre todo, porque los procesos manuales continuos y el uso de la materia prima es obtenida de la región donde habita el artesano. En otras palabras, es un proceso que se ha mantenido por generaciones y en donde la materia prima identifica a la región, ya sea por su producción, cultivo y preparación.

La artesanía se llega a crear como un producto efímero o duradero, pero esa creación llega a tener una función social original que está dada por la cultura misma. Por ejemplo, una artesanía puede llegar a tener usos domésticos, ceremonial, ornato, vestuario o como herramienta de trabajo. Dependerá cómo haya sido concebida por el artesano como se le dará uso socialmente a su creación artesanal.

Esto lo podemos observar con más detalles en la artesanía elaborada en Guatajiagua, Morazán, lugar en donde los artesanos que fabrican utensilios de cocina, empleando barro negro, siguen retando a la modernidad con su diversidad de productos, entre ellos ollas, comales, jarras para café, entre otros. El proceso de elaboración de esta artesanía ha sido mantenido por varias generaciones, utilizando las piedras para lijar el barro, para luego cocinar el barro con los pequeños hornos de leña. Este proceso es muy delicado, requiere de dedicación y productos extraídos de la madre naturaleza.

Teniendo claro lo anterior, debemos preguntarnos: ¿Qué son entonces las manualidades? ¿Es igual la artesanía de la manualidad?

Partamos de la siguiente definición de manualidad: Las manualidades son objetos o productos que resultan de la transformación manual o semi industrializado, a partir de materia prima procesada o prefabricada.

Tanto la técnica como la misma actividad no tienen una identidad o una tradición cultural comunitaria. Este proceso puede ser elaborada por una familia emprendedora como medio de subsistencia, pero la comunidad no se identifica con los productos que se elaboren, lo cual puede tornarse en una labor temporal marcadas por las modas y practicada a nivel familiar o individual.

La creatividad de las manualidades es muy variable, pueden elaborarse artículos sencillos hasta muy complejos, pero carecen de valor cultural y hasta ideológico. Contrario a la artesanía.

Esto resulta fácil identificar, sobre todo cuando se abren mercados improvisados para que los pequeños emprendedores colocan pequeños basares con excelentes manualidades que atraen a muchos. Esto es bueno, pero debemos entender que no es artesanía que fortalezca nuestra cultura y nuestra identidad local o nacional. 
Debo dejar claro que también existe un hibrido entre artesanía y manualidad, donde las personas elaboran sus productos manuales por medio de técnicas artesanales, pero con materiales de la globalización, les asignan un valor ideológico y la comunidad los asume como propios. ¿artesanía? No ¿Manualidad? $\mathrm{Si}$, pero con un valor cultural muy pobre y con un alto grado de consumismo.

¿Por qué es importante que tengamos claro estos dos conceptos?

La respuesta tiene diversas vías, pero yo me centraré en la importancia de definir nuestro producto como artesanía con todas sus características culturales y sociales. Esto ayudará al rescate de nuestro patrimonio cultural, dará más énfasis e nuestra identidad como salvadoreños y permitiremos que nuestros pueblos originarios resurjan del abandono en el cual han sido sumergidos por décadas.

Los artesanos actuales deben estar muy claros ¿cuáles son sus productos? ¿De dónde vienen sus orígenes? ¿cómo se ha heredado la técnica? ¿qué valor tiene para el salvadoreño? y ¿cuánto valor económico tiene en la economía actual?

Estas son preguntas para saber determinar la riqueza patrimonial que hemos heredado y que en muchas ocasiones la hemos olvidado y abandonado.

Tenemos riqueza cultural. Tenemos patrimonio que hizo grandes a nuestros antepasados. Tenemos patrimonio cultural del cual podemos sentirnos orgullosos, pero es necesario que el sector artesanal se reinvente y resurja con fuerza, sobre todo, en momentos muy difíciles en donde la transculturización ya nos borró nuestra identidad; en donde los productos perecederos y desechables inundan nuestro mercado, pero no nos da orgullo, no proporciona valor a nuestra cultura y en donde este tipo de productos nos ha enseñado a desechar, tirar y consumir sin sentido alguno.

Solo como ejercicio mental me gustaría hacer algunas preguntas básicas, las cuales deben ser respondidas por cada uno de ustedes y sacar su propia conclusión:

Cuando usted va a un almacén o mercado local, y desea adquirir alfarería o cerámica para su uso personal o para regalar iencuentra usted un producto hecho manualmente por nuestros artesanos?

Siguiente pregunta:

¿En qué lugar se venden los textiles elaborados por los artesanos salvadoreños? ¿Es una opción para el consumidor salvadoreño?

La madera trabajada por nuestros artesanos, ¿dónde se vende el producto final? ¿Encuentra usted juguetes, muebles o adornos de sala, hechos a mano? 


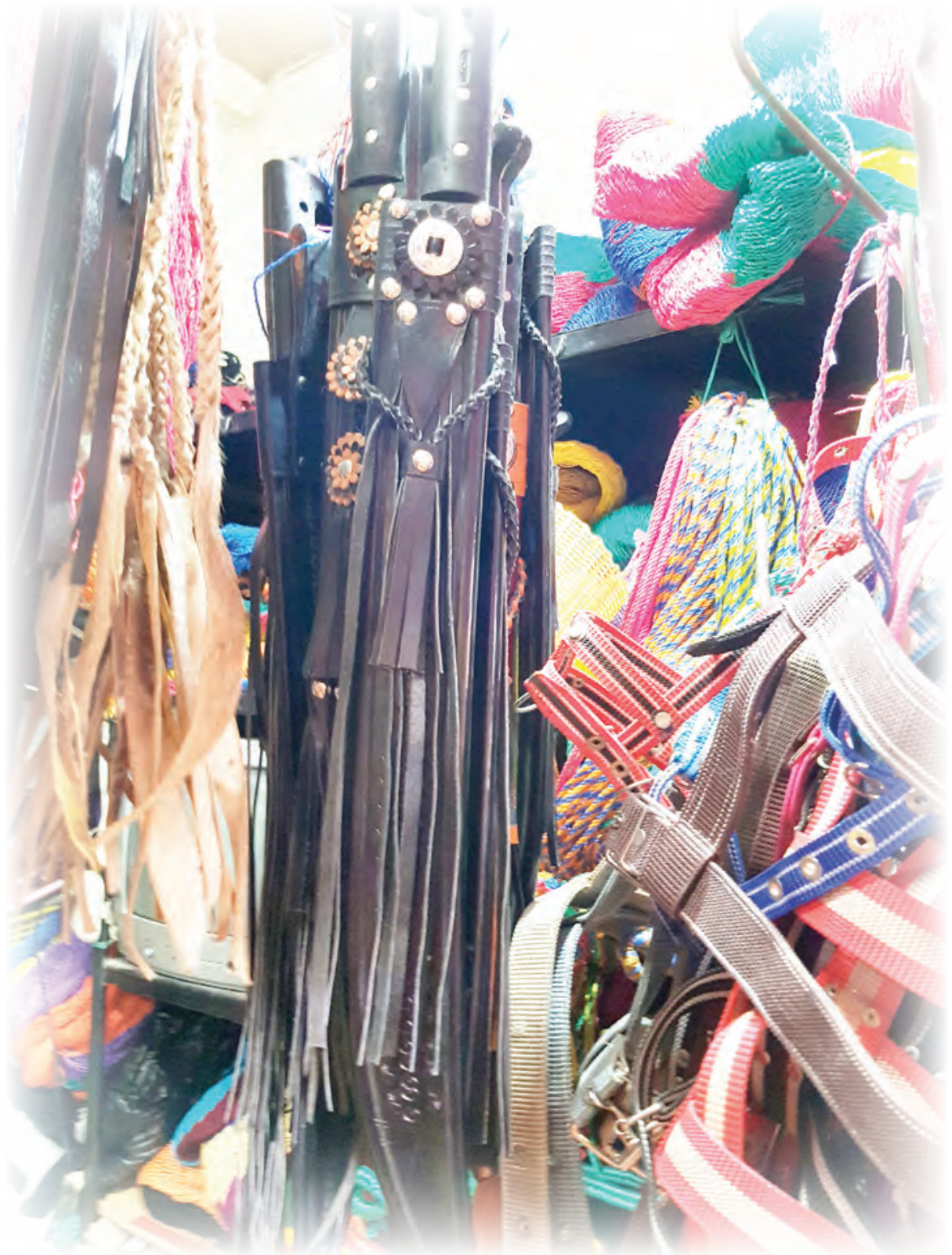

Corbos y guarizamas. Fotografía: Gerardo Herrera. 
¿Dónde están los trabajadores de la metalistería salvadoreña? ¿Será que ya no se trabaja el hierro, cobre, bronce o el latón en nuestros días? ¿Aún existen los orfebres en El Salvador? ¿Dónde están sus productos? ¿Quién los compra en el país?

Todos sabemos que las cestas de mimbre, de fibra de bambú o palmas de coco, cada vez desaparecen. ¿Por qué? ¿Qué ha sustituido al cesto artesanal?

Yo pensaría que el sector artesanal de nuestro país debe iniciar un camino de revalorización de su patrimonio mismo, de saber que son piezas claves para la cultura y el desarrollo de un país.

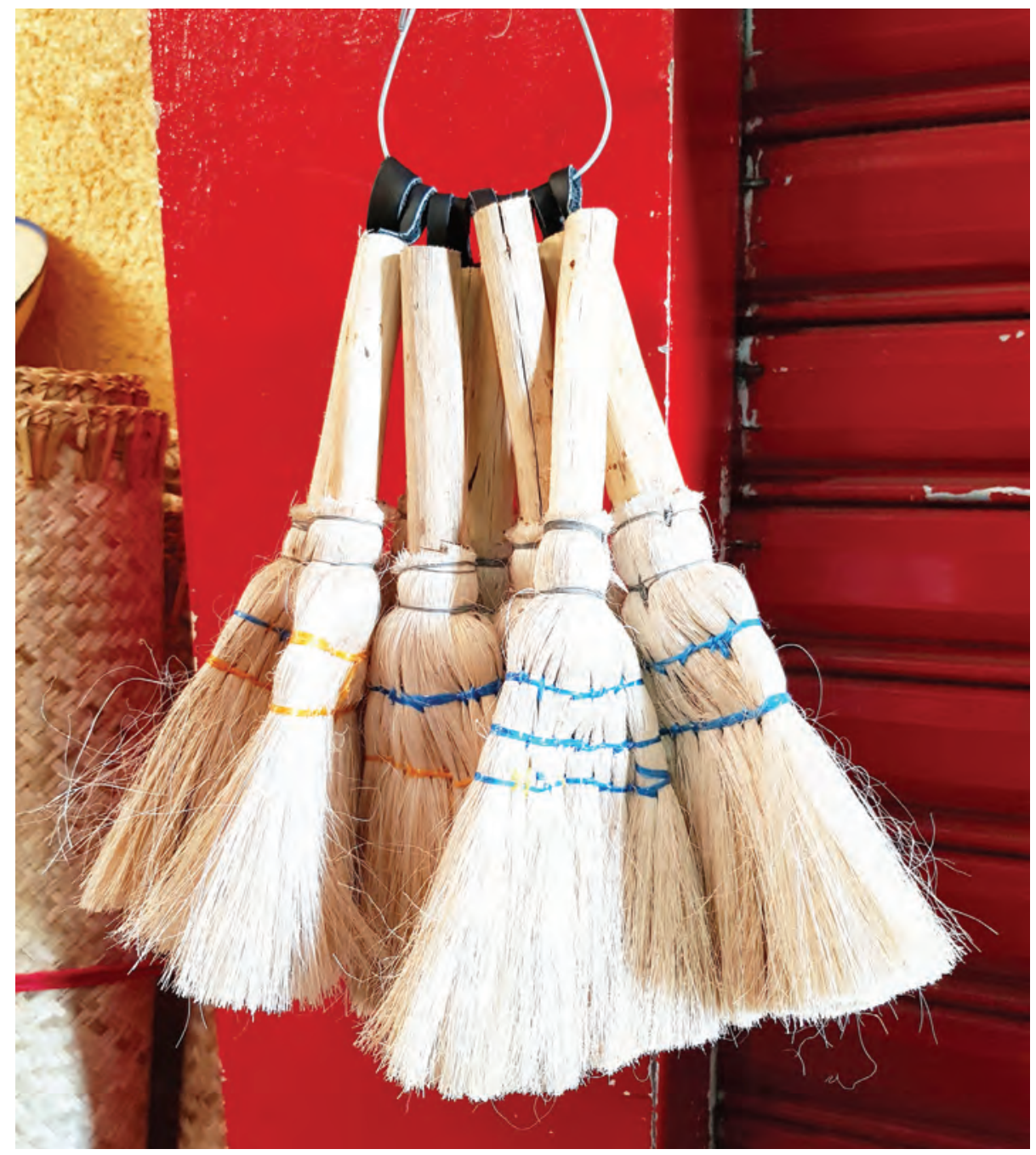

Escobas de mescal. Fotografía: Gerardo Herrera. 


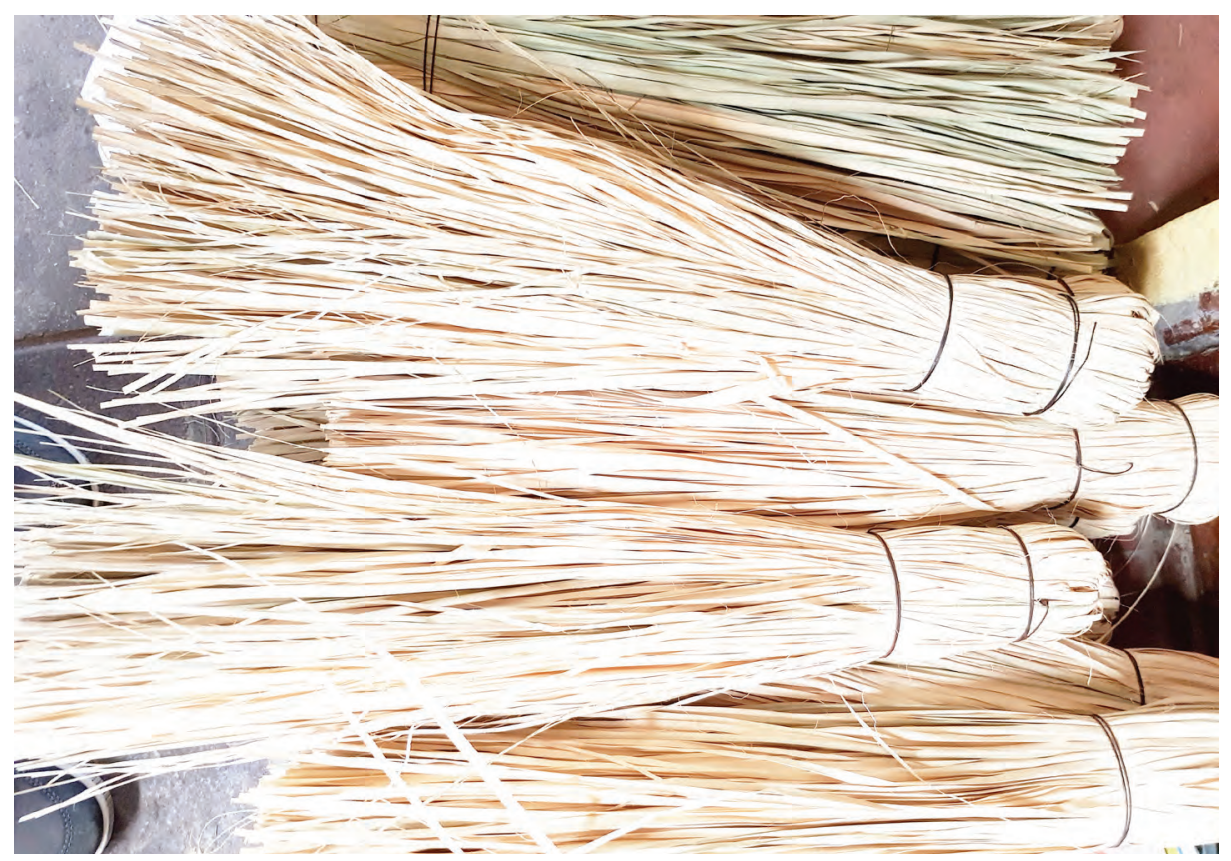

Escobas de palma. Fotografía: Gerardo Herrera.

Para cerrar este artículo comparto la siguiente información estadística que esta disponible al público en general:

$\checkmark$ A nivel gubernamental, no existe un departamento que registre el desarrollo cultural y económico de este rubro. Fue hasta en 1976 que existió el departamento de Etnografía de la Dirección de Patrimonio Cultural que realizó un inventario sobre los centros artesanales de El Salvador.

$\checkmark$ El Desarrollo Artesanal en El Salvador está impulsada por la Comisión Nacional de la Mediana y Pequeña Empresa (CONAMYPE), a través de la Política Nacional para el Desarrollo de la Micro y Pequeña Empresa. Hasta la fecha, solo se han realizado exposiciones de los productos elaborados por algunos sectores artesanales.

$\checkmark$ En Nahuizalco existe un aproximado de 200 talleres artesanales, pero este dato no es oficial.

$\checkmark$ De los 262 municipios existentes en El Salvador, se estima que 240 poseen comunidades artesanales, con un aproximado de 300 mil personas. Este dato lo registró Chang Giselle en su libro "Nuestra artesanía".

$\checkmark$ Según el Ministerio de Economía, el sector artesanal exportó más de 418 mil dólares en el año 2000.La artesanía fue en madera.

$\checkmark$ El Salvador exporta su artesanía de madera a 19 diferentes países del mundo, según datos del Ministerio de Economía para el año 2000. 
$\checkmark$ Un taller artesanal provee trabajo a un promedio de 10 personas, por lo que se ubica dentro de la pequeña empresa nacional.

$\checkmark$ Según el último informe del Banco Central de Reserva, en el 2016 las exportaciones registraron US\$ 404.4 millones, resultando una tasa de crecimiento negativa de $4.7 \%$, con una reducción en el valor de US\$ 20.0 millones; de igual forma el volumen cayó $13.6 \%$.

Con los anteriores datos, lo que busco es que el lector se hagan una idea general de cómo se valoriza este sector, qué se hace por fortalecerlo y su importancia en el sector económico nacional.

\section{Referentes bibliográficos}

Banco Agrícola Comercial de El Salvador. (1997). El Salvador y su riqueza artesanal. San Salvador: Banco Agrícola Comercial de El Salvador.

Banco Central de Reserva de El Salvador. (2016). Informe de comercio exterior de El Salvador. San Salvador: Banco Central de Reserva de El Salvador.

Etienne-Nugue, J. (2009). Háblame de la artesanía. París: Ediciones UNESCO.

Fondo Nacional para el fomento de las artesanías (2009). Manual de diferenciación entre artesanía y manualidades. México, D. F.: Fondo Nacional para el fomento de las artesanías.

Instituto Nacional de Antropología e historia. (2009). Construcción de identidades y visiones del mundo en sociedades. México, D. F.

Menjívar Osorto, M. C. (2009). Impacto del diseño de productos en comunidades de El Salvador que poseen talleres artesanales. Caso de estudio: Guatajiagua, Morazán. Antiguo Cuscatlán: Universidad Dr. José Matías Delgado.

Roncancio, E. (s.f.). Artesanía. Recuperado de http://ftp.unipamplona.edu.co $/ \mathrm{km}$ conocimiento/Copngresos/archivos_de_apoyo/CERTIFICACI\%D3N_ DEL_PRODUCTO_ARTESANAL.pdf 


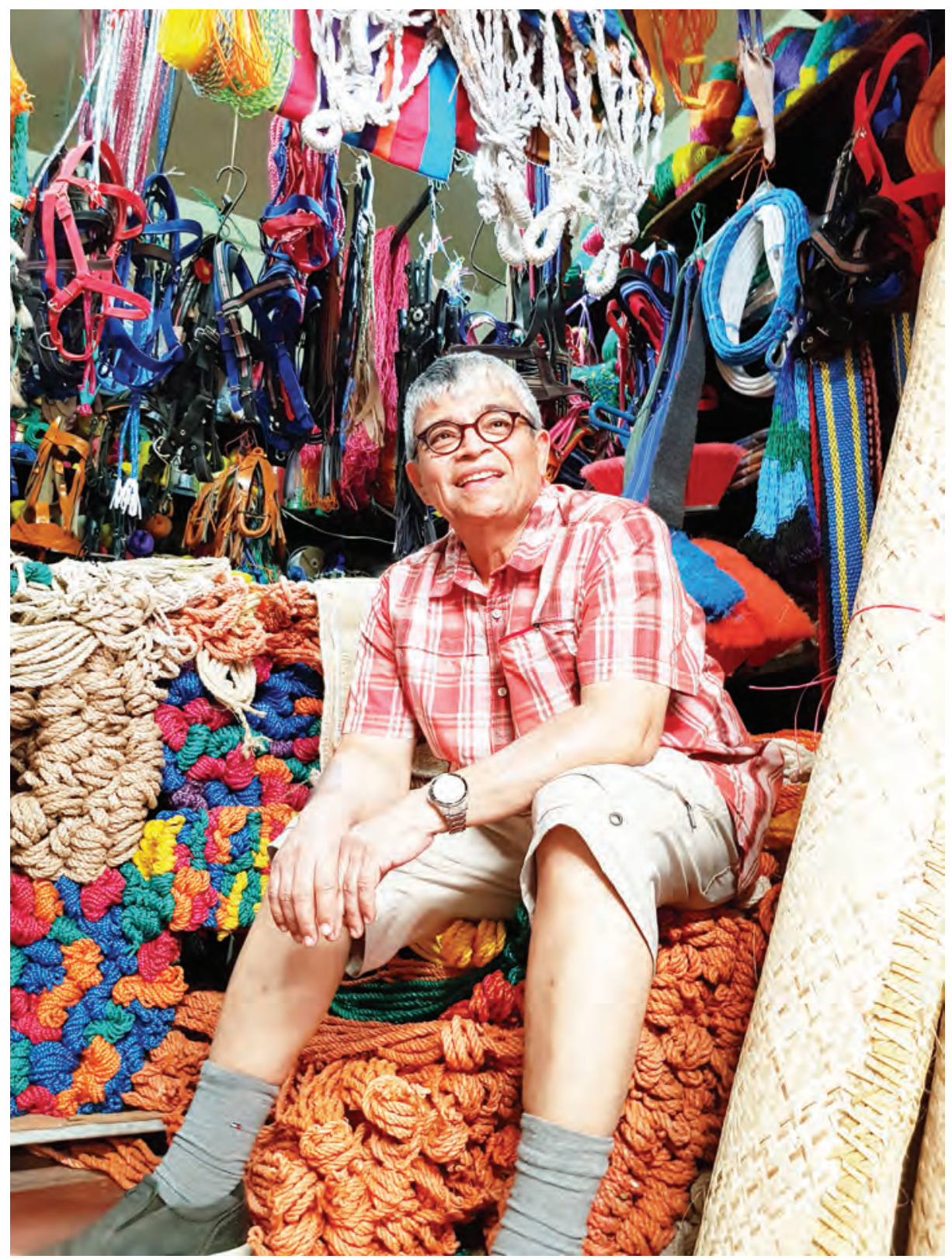

El autor en la tienda de Jarcia, de don Manuel Francisco Estévez. Fotografía: Gerardo Herrera.

El autor agradece la colaboración de doña Rosy de Estévez, por su fina colaboración al recibirnos en la tienda de Jarcia, para la toma de fotografías que enrriquecen este artículo. 